\title{
Logirunner: um Jogo de Tabuleiro como Ferramenta para o Auxílio do Ensino e Aprendizagem de Algoritmos e Lógica de Programação
}

\author{
Romeu Isaac Casarotto ${ }^{1}$, Giliane Bernardi' ${ }^{2}$, Andre Zanki Cordenonsi ${ }^{3}$, Roseclea Duarte Medina ${ }^{4}$ \\ ${ }^{1}$ Curso de Sistemas de Informação - UFSM - rcasarotto@inf.ufsm.br \\ ${ }^{2}{ }^{4}$ Departamento de Computação Aplicada - UFSM - \{giliane,rose $\} @$ inf.ufsm.br \\ ${ }^{3}$ Departamento de Documentação - UFSM - andrezc@inf.ufsm.br
}

Resumo: Disciplinas que envolvem lógica e algoritmos costumam ser introduzidas aos estudantes dos cursos de tecnologia logo nos primeiros semestres. Atualmente, o método de ensino expositivo está sujeito a um comum desestímulo, abrindo espaço para possíveis rupturas no fluxo da informação e aprendizagem. Considerando este contexto, este trabalho apresenta uma proposta de jogo de tabuleiro educacional, Logirunner, que visa auxiliar neste processo, trazendo uma abordagem que busca motivar os estudantes a reforçar conteúdos vistos em aula. Um protótipo do jogo Logirunner foi idealizado com elementos físicos reais, cartas, peças e tabuleiro, para ser utilizado em sala de aula. Foram então inseridos em suas regras elementos de lógica de programação e algoritmos, conteúdo a ser reforçado durante as sessões de jogo. Como principais contribuições dessa avaliação, é possível destacar que o jogo proposto proporcionou uma experiência bastante didática e descontraída ao ser levado para dentro da sala de aula, satisfazendo as intenções iniciais desta pesquisa.

Palavras-chave: Jogo Educacional, Algoritmos, Jogos de Tabuleiro

\section{Logirunner: A Board Game to Teach and Learn Algorithms and Logic Programming}

Abstract: Disciplines involving logic and algorithms are often introduced to technology students as early as the first semesters. Currently, the expository teaching method is subject to a common discouragement, opening space for possible ruptures in the flow of information and learning. Considering this context, this paper presents the Logirunner, an educational board game proposal. The main objective is to help the educational process, bringing an approach that motivates students to reinforce the contents instructed in classroom. A prototype of the game was designed with real physical elements, cards, pieces and a board. Elements of logic programming and algorithms were inserted into their rule to reinforce these concepts during game sessions. As the main contributions of this paper, it is possible to emphasize that the game proposed provided a rather didactic and relaxed experience in the classroom, satisfying the initial intentions of the research.

Keywords: Educational Games, Algorithms, Board Games

\section{Introdução}

Disciplinas que envolvem algoritmos e lógica de programação possuem um significativo número de reprovações e desistências, como pode ser observado em Giraffa et al. (2016). A quantidade e complexidade das informações novas a serem absorvidas pelos estudantes acabam se tornando confusas e, consequentemente, geram interferências na aprendizagem (Deters et al., 2008). Para minimizar esta situação, uma 
das alternativas é desenvolver um componente extra que estimule o interesse e a atenção dos alunos pela disciplina, e também auxilie a reforçar o conteúdo, servindo como uma interface divertida e intuitiva aos conceitos que precisam ser aprendidos.

Existem certas atividades que despertam grande interesse nos jovens, mesmo que não sejam de importância vital ou acadêmica e que, de uma forma ou de outra, motivados e engajados, os participantes acabam aprendendo muito sobre as regras e procedimentos que as compõem. Dito isso, pode-se destacar os jogos como um exemplo destas atividades, que além de proporcionarem momentos de diversão, são estudados há anos como ferramentas de ensino e desenvolvimento de conceitos e habilidades (Juan et al., 2017). Considerando a falta de interesse dos alunos por certos conteúdos e a conveniente característica que os jogos possuem de despertar interesse e atenção, é necessário estudar maneiras de agregar, de forma eficiente, conceitos acadêmicos em jogos, para que possam ser utilizados dentro e fora das salas de aula, de forma que o conteúdo seja espontaneamente reforçado e absorvido pelos alunos. Para viabilizar tal integração, é necessário que os conteúdos acadêmicos façam parte da mecânica do jogo (Von Wangenheim et al., 2012), e não apenas figurem como uma temática, provendo aos jogadores desafios verdadeiros, elaborados e embebidos de conceitos essenciais e necessários. Considerando o exposto acima, este trabalho apresenta uma proposta de jogo educacional de mesa, denominado Logirunner, que reúne elementos físicos reais, cartas, peças e tabuleiro, contemplando também em seu sistema elementos de lógica e programação. O jogo proposto busca motivar os estudantes servindo como uma ferramenta de auxílio ao processo de ensino e aprendizagem, tornando a prática das competências de lógica e criação de algoritmos uma atividade leve, divertida e descontraída, a ser aplicada tanto dentro quanto fora das salas de aula.

\section{Pensamento Computacional e Algoritmos}

O Pensamento Computacional (PC) é um dos alicerces para o desenvolvimento de disciplinas ligadas à lógica e programação. Em Wing (2014), a autora afirma que PC engloba os processos de pensamento envolvidos na formulação de um problema e que expressam sua solução ou soluções eficazmente, de tal forma que uma máquina ou uma pessoa possa realizar. Já em Brackmann (2017), temos que o Pensamento Computacional é uma distinta capacidade criativa, crítica e estratégica humana de saber utilizar os fundamentos da Computação, nas mais diversas áreas do conhecimento, com a finalidade de identificar e resolver problemas, de maneira individual ou colaborativa, através de passos claros, de tal forma que uma pessoa ou uma máquina possam executálos eficazmente. Segundo Boucinha et al. (2017), o Pensamento Computacional tem sido comparado com a alfabetização do século XXI e possuir habilidades básicas de codificação tornou-se algo necessário para muitos postos de trabalho. Os autores apresentam que estudos da European Commission de 2015 estimam que 90\% das ocupações profissionais hoje em dia requerem competências digitais, incluindo programação.

$\mathrm{Na}$ área do ensino da Computação, não é difícil entender o quão importante é o Pensamento Computacional. Praticamente todas as atividades da área exigem esforços para solucionar problemas ou evitá-los. Em ambos os casos, tanto para a solução quanto para a prevenção de problemas, se faz necessário o emprego adequado das habilidades de lógica e compreensão de algoritmos. Portanto, é um dever do profissional da área capacitar-se, aprender a ler, entender, desenvolver e utilizar algoritmos, sejam eles em forma de códigos ou metodologias, assim como um desafio aos docentes encarregados 
de capacitar e guiar estes profissionais ao longo do processo de graduação. As competências de algoritmos e lógica de programação, apesar de poderem ser praticadas e desenvolvidas na infância e adolescência, acabam recebendo atenção apenas quando o aluno ingressa no ensino superior. Este contato súbito e tardio com as disciplinas de lógica e algoritmo pode potencializar dificuldades na absorção do assunto, sendo importante encontrar abordagens de ensino que contornem ou amenizem tais dificuldades. De acordo com Deters et al. (2008), estas disciplinas são consideradas desafiadoras pelos alunos, pois exigem o desenvolvimento de estratégias de solução de problemas com base lógico/matemática e, como consequência, presenciamos um elevado número de problemas de aprendizagem, favorecendo a ocorrência de reprovações e desistências. Para tanto, foi realizado um estudo dos principais conceitos necessários para a correta compreensão dos algoritmos e que são base do jogo desenvolvido, sendo que o mesmo contemplou três destes conceitos: estrutura sequencial de comandos, estruturas condicionais e estruturas de repetição.

\section{Trabalhos Correlatos}

Foram analisados três trabalhos correlatos ao apresentado neste artigo. O primeiro deles, Master, é um jogo de tabuleiro criado por Mark Engelberg e distribuído pela empresa Thinkfun, que usa elementos lúdicos simbólicos para reter a atenção do jogador e desafiá-lo a alcançar seus objetivos. Ele pode ser jogado por apenas um jogador ou de maneira colaborativa, pois permite a formação de um grupo de jogadores onde todos podem dar palpites e sugerir rotas a serem seguidas pelo personagem. $\mathrm{O}$ jogo tem como objetivo orientar o avatar do jogador pelo mapa e fazê-lo chegar até o Portal que conduz ao próximo nível. No início de uma partida, o jogador recebe um mapa que indica onde seu avatar deve começar, a localização de Cristais (elementos de jogo) e o Portal para o próximo nível. Utilizando então o Pergaminho Guia e um número limitado de tokens de Ação, deve-se compor um programa que guiará o personagem através de uma espécie de grafo, cheio de ligações coloridas representadas pelas mesmas cores dos tokens de Ação (Thinkfun, 2015).

Já o Lightbot é um jogo onde um robô busca acender todas as luzes de seu mundo, sendo considerado um jogo de resolução de problemas (Yaroslavski, 2014). Ele parece apenas um quebra-cabeças tradicional, mas a mecânica apresenta conceitos de programação. O objetivo é guiar o pequeno robô para acender todas as casas azuis (luzes) em cada uma das diferentes fases do jogo. Para fazer isso, é preciso "programar" o pequeno robô utilizando um conjunto de instruções. Finalmente, o Jump, Step, Step (http://store.steampowered.com) tem características bastante similares ao jogo Lightbot. O jogo apresenta uma série de desafios em que o jogador deve utilizar elementos de programação (blocos de instruções) para superar diversos níveis e obstáculos. Desenvolvido por Thang Phung Dinh e Dzung Phung Dinh, este jogo tem como personagem principal Bob, um robô em curto circuito incapaz de voltar sozinho à sua nave, ficando a cargo do jogador a missão de enviar instruções lógicas para guiá-lo. Todos os trabalhos apresentados possuem objetivos e elementos semelhantes, mas nenhum deles possui de fato a característica de multijogador. Vale destacar também que os jogos mais completos costumam ser disponibilizados apenas em versões digitais. Logo, Logirunner se destaca como uma opção não digital e por comportar mais de um jogador, aspecto importante para ser levado às salas de aula. 


\section{Metodologia}

Este trabalho iniciou com uma revisão bibliográfica de diferentes trabalhos relacionados com a aprendizagem de algoritmos e pensamento computacional. Observou-se, após a análise de trabalhos correlatos, quais eram os elementos de jogos abordados pelas ferramentas para ensinar lógica e programação, sendo realizada uma análise de características que poderiam acrescentar maior motivação para os alunos usuários do Logirunner. Munindo-se das informações absorvidas nas etapas anteriores, passou-se à fase de definição das estruturas lógicas de programação a serem trabalhadas no jogo, bem como o formato e a dinâmica necessária para contemplar estes conceitos. Considerando os requisitos deste trabalho, portabilidade, facilidade de utilização em salas de aula, jogos similares e suas características em comum, acabou-se optando por um jogo físico, que envolvesse elementos de cartas, personagens e tabuleiro, sendo então desenvolvido um protótipo inicial do jogo proposto, seguido de diversos ajustes e melhorias de balanceamento e jogabilidade. Tendo duas cópias do protótipo em mãos, foram realizadas cinco sessões de jogos com vinte alunos voluntários matriculados na disciplina de Lógica e Algoritmo do primeiro semestre dos cursos de Ciência da Computação e Sistemas de Informação da UFSM. Com o objetivo de coletar subsídios para analisar a estratégia de avaliação utilizada foi utilizada a abordagem MEEGA+, um modelo de avaliação de jogos educacionais proposto por Petri et al. (2016). Como instrumento para coleta de dados, utilizou-se um questionário desenvolvido pelos autores do modelo de avaliação, que tem como foco a avaliação da qualidade de jogos não-digitais.

\section{Logirunner: Projeto e Desenvolvimento}

Logirunner é um jogo multijogador baseado em turnos, planejado para comportar um grupo de até quatro jogadores. Basicamente, se trata de uma corrida onde os jogadores passam instruções de movimento a seus personagens (runners) e estes devem concluir um circuito de objetivos (checkpoints) em um mundo representado por um tabuleiro quadriculado, semelhante ao utilizado em partidas de xadrez. Os principais elementos do jogo são apresentados a seguir.

\subsection{Tabuleiro \& Checkpoints}

O tabuleiro é a base que dará suporte a todos os runners e obstáculos, onde também estão fixados os checkpoints, que são os objetivos parciais do jogo. Inspirado no conhecido tabuleiro utilizado nos jogos de xadrez e damas, o tabuleiro do jogo Logirunner possui 16 linhas e 16 colunas, o que permite a indexação de todas suas casas por um conjunto de dois algarismos hexadecimais, cada um representando linha e coluna, de 00 à FF. A figura 01(a) apresenta uma visão superior do tabuleiro utilizado neste jogo. Destacam-se neste tabuleiro os quatro checkpoints, ponto de partida da jornada de cada um dos runners. Cada checkpoint possui o símbolo de seu respectivo runner. A partir do início do jogo, o jogador deverá utilizar as cartas adquiridas para criar algoritmos de movimento e fazer seu runner percorrer os demais checkpoints até retornar ao seu ponto de partida, completando o jogo.

\subsection{Runners e Buracos}

Os runners, ou avatares, são as peças que representam o progresso do jogador na partida. É a partir deles que são iniciados os movimentos definidos em cada execução de uma sequência de comandos criada por um jogador. São eles que percorrem o 
tabuleiro em busca dos checkpoints e são representados pelos ícones da figura 01(b). Já os buracos são os obstáculos do jogo, elementos que buscam aumentar o nível de desafio, para que o jogo não se torne apenas uma corrida em um tabuleiro vazio. Uma partida inicia sem buracos dispostos no tabuleiro (figura 01/c).

Figura 01 - Elementos do Jogo
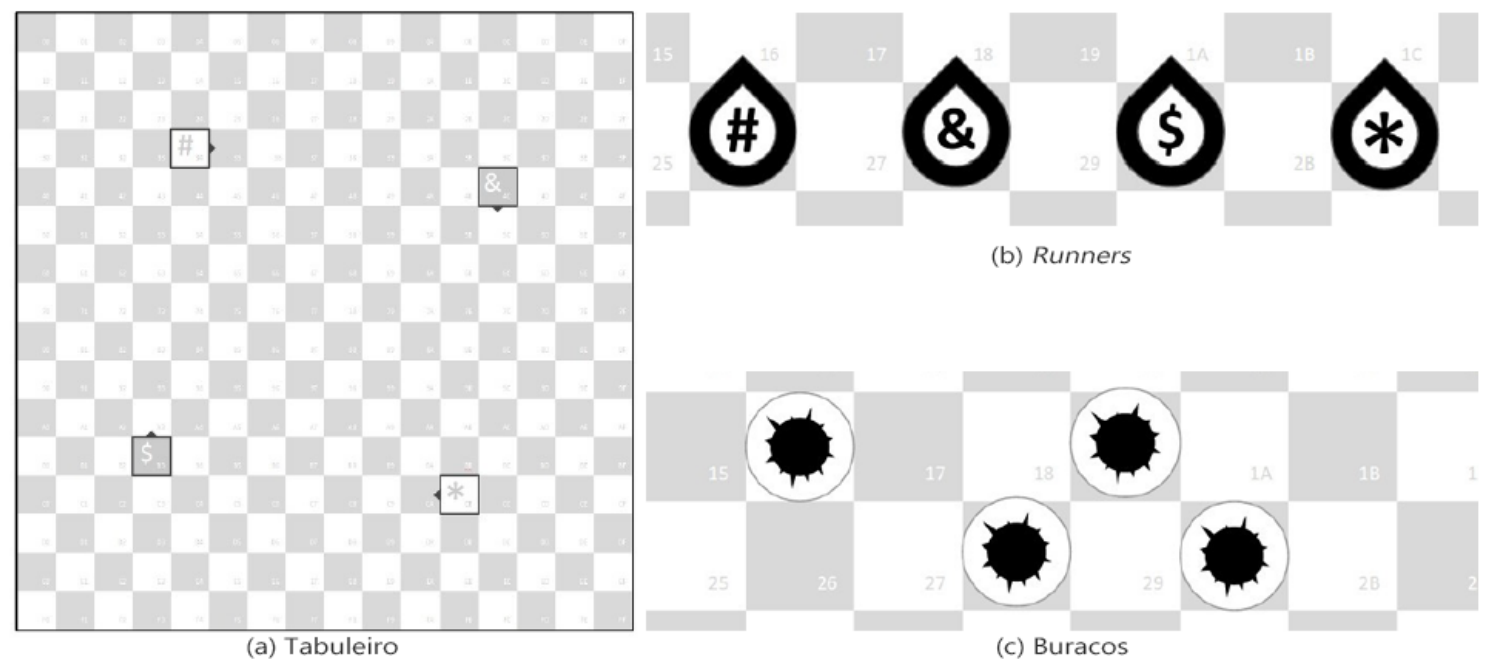

(b) Runners

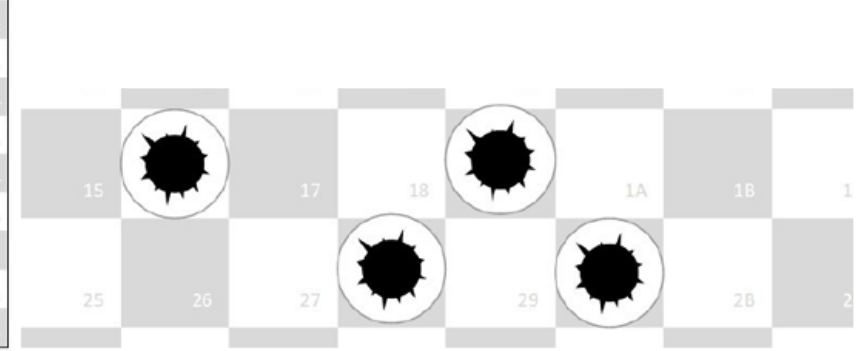

(c) Buracos

\subsection{Cartas}

As cartas são os elementos fundamentais do jogo. Cada carta possui informações e instruções indicando o tipo de carta (Cartas de Comando, Cartas de Condição, Cartas de Repetição ou Ação Instantânea - AI) e uma breve instrução de seu funcionamento. Todas as cartas possuem uma imagem e um texto ilustrativo (decorativo), que buscam imergir o jogador no universo do jogo e tornar a experiência mais agradável.

As Cartas de Comando disponíveis são Corra (desloque o runner uma casa para frente), Pule (desloque o runner duas casas para frente), Vire à Direita (gire o runner para a frente da casa à direita) e Vire à Esquerda (gire o runner para a frente da casa à esquerda) (figura 02/a). Para utilizá-las, basta que o jogador as posicione em sua frente durante a sua fase de ação. As Cartas de Condição disponíveis são $S e$ - Buraco à frente (executa se houver um buraco à frente), Se - Caminho à frente (executa se houver um caminho à frente) e Senão (estrutura vinculada a um dos dois $S E$ anteriores) (figura 02/b). Para utilizá-las, o jogador posiciona as mesmas à sua frente e vincula às instruções que deseja realizar quando as condições forem satisfeitas. Já as Cartas de Repetição disponíveis são Repetir $2 x$ e Repetir $3 x$ (figura02/c). Da mesma forma que as Cartas de Condição, para utilizá-las o jogador deve vincular às instruções que deseja realizar. Além destas, há duas Cartas de Ação Instantânea: Bug (que permite que o jogador insira uma carta da sua mão no código de qualquer outro jogador) e Debug (que é utilizada para remover uma carta de Bug). Estas duas cartas permitem explorar as características de jogabilidade do LogiRunner.

\subsection{Resumo das regras}

A cada início de partida são distribuídas aleatoriamente oito cartas para cada jogador, que também deve posicionar o seu runner (peão) em um dos quatro checkpoints do tabuleiro. O objetivo do jogador é ser o primeiro a percorrer os outros três checkpoints e 
retornar à sua posição original. $\mathrm{O}$ jogo ocorre numa sequência de turnos onde, em cada turno, o jogador pode:

a) editar o seu programa: colocar cartas da sua mão para a área de código imediatamente à sua frente, em uma sequência lógica; não é permitido baixar cartas iguais, mas é possível mover ou remover cartas do código implementado;

b) executar o programa: se o código está completo, o jogador pode executar o programa, seguindo a sequência lógica definida. Caso o runner caia em um buraco, a ação é interrompida imediatamente;

c) manutenção: o jogador deve adquirir, do baralho de cartas, o número suficiente para que fique com oito cartas em sua mão. Caso ele tenha realizado a ação de executar o programa satisfatoriamente, então ele também pode pegar um buraco e colocá-lo em qualquer lugar do tabuleiro.

As ações instantâneas (Bug e Debug) podem ser realizadas pelo jogador a qualquer momento do jogo.

Figura 02 - Cartas do Jogo

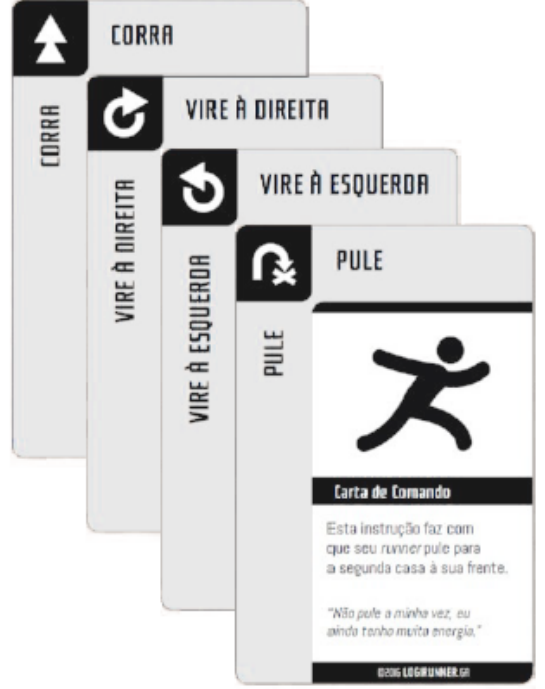

(a) Cartas de Comando

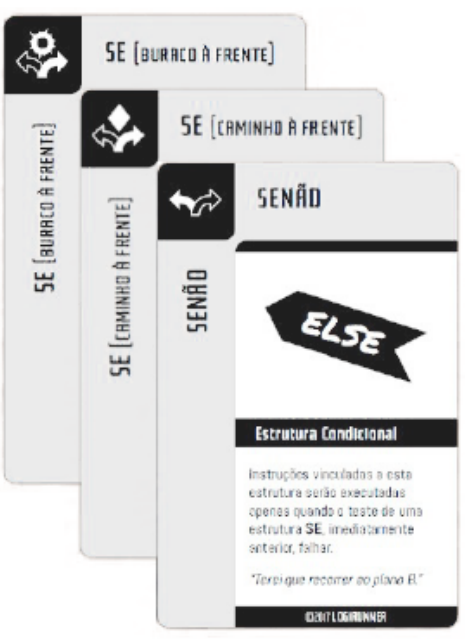

(b) Cartas de Condição

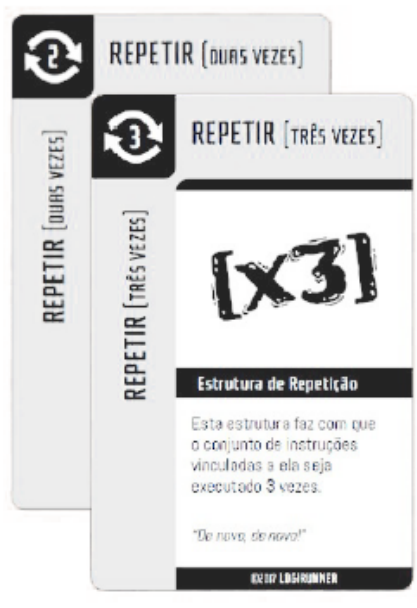

(c) Cartas de Repetição

\section{Avaliação}

Foi realizada uma aplicação do jogo Logirunner junto a estudantes voluntários matriculados na disciplina de Lógica e Algoritmo, ofertada no primeiro semestre dos cursos de Ciência da Computação e Sistemas de Informação da UFSM. Por se tratar de uma proposta de jogo educacional não-digital para uso em sala de aula, optou-se por uma aplicação presencial, como uma atividade de aula, planejada em conjunto com o docente responsável pela turma. Cada partida durou entre 35 a 65 minutos. Foram utilizados como instrumentos para a coleta de dados a observação presencial dos pesquisadores durante as aplicações do jogo e o modelo de avaliação de jogos educacionais MEEGA+. Durante os dois dias da atividade, foram realizadas cinco aplicações do jogo com quatro alunos distintos em cada uma delas, alcançando um total de vinte (20) estudantes, dos quais dezessete (17) entregaram o formulário de avaliação preenchido. Em ambos os dias obedeceu-se a seguinte abordagem de aplicação: a) realização de uma apresentação do trabalho e do jogo proposto à turma; b) definição dos oito alunos que participariam de cada jogo; c) organização do ambiente, onde foram 
dispostas mesas, cadeiras e os elementos do jogo para dar início às sessões de avaliação; d) esclarecimento das instruções de funcionamento do jogo, em conjunto com a entrega de um curto manual (um para cada jogador) para consulta de regras e objetivos; e) início das partidas; f) acompanhamento das partidas pelos pesquisadores, para recolher observações pertinentes e sanar possíveis dúvidas dos jogadores no decorrer da atividade; g) apresentação e distribuição dos formulários de avaliação impressos, para serem preenchidos e posteriormente recolhidos. O formulário apresentava diversas afirmações, onde o estudante tinha cinco opções de escolhas referentes a quanto o jogador concorda ou discorda da mesma, de acordo com a escala Likert (1932) de pontuação, também utilizada por Gouws et al. (2013) em sua avaliação do jogo educacional Lightbot. Os dados estão compilados na figura 03.

As perguntas 1 a 9 referem-se à Experiência do Jogador e Usabilidade. Neste primeiro grupo, destacam-se duas afirmações que obtiveram $100 \%$ de avaliações positivas (Concordo e Concordo Fortemente): Aprender a jogar este jogo foi fácil para mim (04) e As fontes (tamanho e estilo) utilizadas no jogo são legíveis (08). No conjunto, houve $84 \%$ de avaliações positivas (Concordo e Concordo Fortemente) para todo o grupo. As questões 10 e 11 representam aspectos de confiança percebidos pelo jogador. Novamente, é notável a predominância de avaliações positivas de peso 1 e 2 (Concordo e Concordo Fortemente), totalizando mais de $73 \%$ para todo o grupo, apesar de um jogador discordar da forma como o jogo foi apresentado. O próximo grupo (questões 12 a 14) representa afirmações referentes à percepção de desafio, que também obteve resultados bastante positivos, totalizando $82 \%$ de aprovação. Desta forma, podese afirmar que, para os avaliadores, o jogo aparenta ser adequadamente desafiador e oferece novos desafios com um ritmo adequado. Um aspecto essencial a ser avaliado, a satisfação, tem seus resultados expostos pelas questões 15 a 18, onde pode ser constatado uma marca de $91 \%$ em avaliações positivas. Aqui destacam-se duas das quatro afirmações do grupo, que alcançaram 100\% de aprovação (questões 17 e 18). Aqui pode-se fazer referência a um dos principais objetivos do jogo proposto, incentivar o reforço espontâneo das competências acadêmicas, pois a satisfação é um fator determinante para atrair a atenção dos jogadores e mantê-los engajados na atividade.

Outra particularidade do jogo Logirunner é sua característica multijogador, que incentiva a interação social entre os estudantes, aspecto contemplado pela análise das questões 19 a 21 . A taxa de avaliações positivas de todos os grupos é de $96 \%$, com destaque de mais de $62 \%$ de avaliações do tipo "Concordo fortemente". Fator de grande importância no contexto de jogos educacionais, a avaliação do quesito Diversão é representadas pelas questões 22 e 23 . Observamos um total de $94 \%$ de avaliações positivas, com destaque para as longas barras de avaliações do tipo "Concordo fortemente" que juntas equivalem à quase $72 \%$ do total, apesar de um jogador não ter "sorrido durante o jogo".

Já a Atenção Focada, que é representada pelas questões 24 a 26, foi o único subgrupo que recebeu avaliações negativas do tipo "Discordo fortemente". Como resultados gerais deste grupo, o total de avaliações positivas alcançou uma taxa de quase $69 \%$ das avaliações, seguida de $21 \%$ de avaliações neutras e $10 \%$ de avaliações negativas. No grupo de Percepção de Relevância, visualizado a partir das questões 27 a 30 , obteve-se um total geral de $88 \%$ de avaliações positivas e dá-se especial atenção às três primeiras afirmações, que alcançaram 100\% de avaliações positivas. Quanto a 
última afirmação deste grupo (questão 30), apesar de apresentar um resultado de apenas $53 \%$ de avaliações positivas, é importante lembrar que o objetivo do jogo é atuar como ferramenta de auxílio ao processo de ensino e aprendizagem, não tendo intenção de substituir o mesmo. Por fim, as questões 31 a 33 apresentam a Percepção de Aprendizagem dos avaliadores. As questões 31 e 32 totalizaram uma taxa de $85 \%$ de aprovação, seguido de $15 \%$ de avaliações neutras e a última questão obteve $100 \%$ de aprovação, resultado que serve de apoio aos objetivos deste trabalho.

Figura 03 - Síntese dos Resultados Obtidos

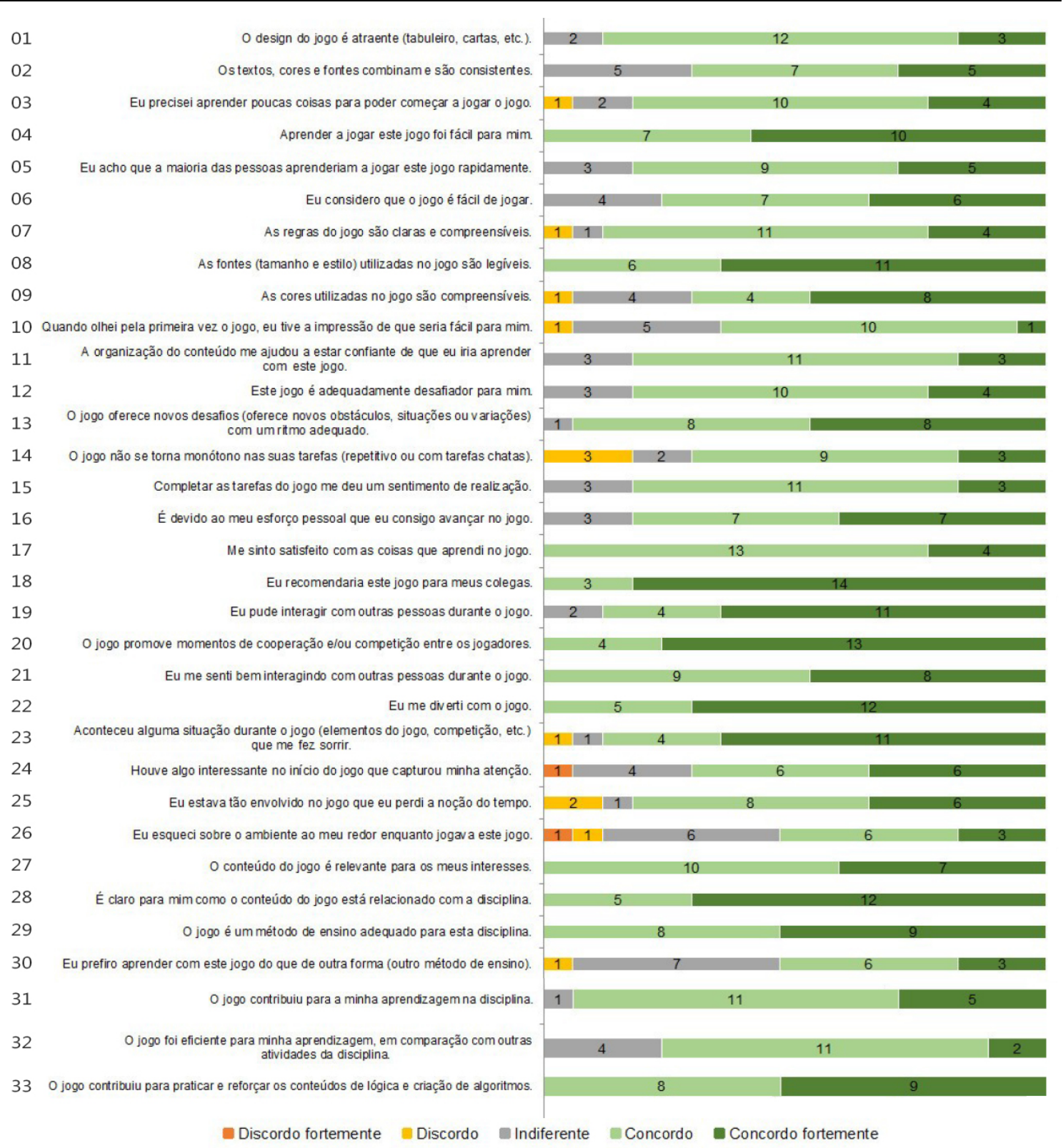

De modo geral, pode-se observar que os pontos fortes convergiram para as questões de interação, diversão e aprendizagem. Nas sugestões de melhoria, repetiramse solicitações para acrescentar tempo às jogadas, novas cartas e desafios, assim como melhorar a interação com os runners e criar uma versão colorida do jogo. Destacam-se também os elogios e recomendações registrados nos comentários gerais, onde os 
estudantes relataram se tratar de uma boa maneira de abordar o conteúdo e introduzi-lo a novos alunos. Ainda, pode-se verificar que dentre as 561 afirmações avaliadas pelos 17 estudantes, $85.56 \%$ destas receberam conceito positivo, restando $14.44 \%$ de avaliações neutras ou negativas. Acrescenta-se também, com base nas observações do pesquisador feitas durante o andamento das partidas, que o jogo proposto despertou grande interesse nos estudantes, os quais demonstraram-se comprometidos com a partida e permaneceram engajados em seus objetivos até o final da atividade.

\section{Conclusões}

Jogos sempre fizeram parte de nossas vidas e normalmente estão vinculados a lembranças agradáveis e diversão. Estão cada vez mais presentes no meio acadêmico e ainda devem continuar nos servindo de inspiração para solucionar ou minimizar diversos problemas do nosso cotidiano, como serviram à construção desta proposta. Neste trabalho foi proposto um protótipo de jogo educacional que visa motivar os estudantes a reforçar os conteúdos vistos em aula e auxiliá-los a adquirir competências na área de lógica de algoritmos. Como um dos objetivos, buscava-se estimular os estudantes a praticar, de forma divertida e interativa, estes conceitos acadêmicos e despertar maior interesse pelas disciplinas, de maneira a reduzir os índices de reprovações e desistências. Pelos resultados apresentados, é possível afirmar que os estudantes consideraram a interação, diversão e aprendizagem como os pontos fortes do jogo, formando um tripé de sustentação para a aplicação do Logirunner: a) interação entre estudantes, um aspecto importantíssimo na construção de algoritmos, pois cada vez mais é necessário o desenvolvimento de habilidades cooperativas para times de desenvolvimento de software; b) aprendizagem, aspecto primordial para um jogo educativo, que se propõe a auxiliar o ensino de uma determinada área; c) diversão, pois o aspecto lúdico do jogo não pode ser ignorado e é a principal força motriz na utilização desta metodologia.

No processo de desenvolvimento do jogo Logirunner foram indispensáveis os estudos das alternativas atuais de ensino, assim como a análise de outros jogos que compartilham dos mesmos objetivos. Foi preciso também entender um pouco mais sobre as disciplinas e definir quais os elementos básicos a serem incorporados, as estruturas de programação, os conceitos lógicos e o processo de criação de algoritmos. Tudo foi estudado, planejado e desenvolvido com a intenção de proporcionar aos estudantes uma experiência verdadeiramente divertida, interativa e social, que fosse capaz de conciliar o mundo acadêmico ao mundo dos jogos e dar um novo significado ao exercício do ensino e da aprendizagem. Como resultado de tudo isso, apresenta-se um protótipo de jogo educacional que mostrou-se apto a cumprir seus objetivos e intenções iniciais, reunindo diversos elementos e referências, como tabuleiro, cartas, personagens e obstáculos, em um sistema simples e aderente à realidade das salas de aula. A atividade de avaliação realizada com os alunos da disciplina de lógica e algoritmos refletiu precisamente toda a intenção aplicada a este projeto, que, apesar de ainda necessitar ajustes e revisões, promoveu uma experiência agradável e promissora a todos os envolvidos. Acrescentam-se, ainda, observações a respeito do importante papel 
exercido pelo modelo de avaliação de jogos educacionais MEEGA+, ferramenta que auxiliou o processo de coleta e análise das avaliações aqui expostas. Acrescentam-se também a esta conclusão, algumas possíveis ramificações deste trabalho a serem postas em prática futuramente. A revisão do balanceamento do jogo, a expansão e adaptação do conteúdo, cartas e ações a outras estruturas de lógica e programação, além de realizar estudos mais profundos sobre os efeitos e contribuições de sua aplicação às disciplinas iniciais de lógica e programação estão entre os possíveis trabalhos futuros.

\section{Referências}

BOUCINHA, R. M., BRACKMANN, C. P., BARONE, D. A. C., CASALI, A. Construção do Pensamento Computacional Através do Desenvolvimento de Games. Renote, Porto Alegre, v. 15, n. 1. 2017.

BRACKMANN, C.P. Desenvolvimento do Pensamento Computacional através de Atividades Desplugadas na Educação Básica. Tese de Doutorado, PPGIE, 2017.

DETERS, J.I., et al. O desafio de trabalhar com alunos repetentes na disciplina de Algoritmos e Programação. In: Workshop de Ambientes de apoio à Aprendizagem de Algoritmos e Programação. 2008.

FURLAN, M.A. et al. Algoritmos e Lógica de Programação. São Paulo: Cen. Learning, 2012.

GIRAFFA, L.M.M., MORA, M.C., Evasão na disciplina de algoritmo e programação: um estudo a partir dos fatores intervenientes na perspectiva do aluno. In: III Conferencia Latinoamericana sobre El Abandono em La Educación Superior, 2016.

GOUWS, L., BRADSHAW, K., WENTWORTH, P. Computational Thinking in Educational Activities: an evaluation of the educational game Light-bot. In: Proceedings of the $18^{\text {th }}$ ACM Conference on Innovation and Technology in Computer Science Education. p. 10-15, 2013.

JUAN, A.A., LOCH, B., DARADOUMIS, T., VENTURA, S. Games and Simulation in Higher Education. International Journal of Educational Technology in Higher Education, v. 14, n. 37, 2017.

KOSCIANSKI, A., GLIZT, F. R. O. O Pensamento Computacional nos Anos Iniciais do Ensino Fundamental. Renote, Porto Alegre, v. 15, n. 2. 2017.

LIKERT, R. A technique for the measurement of attitudes. Archives of psychology, 1932.

PETRI, G., VON WANGENHEIM, C., BORGATTO, A. MEEGA+: An Evolution of a Model for the Evaluation of Educational Games. In: INCoD/GQS. 2016

THINKFUN. Code Master. 2015. Disponível em: <http://www.thinkfun.com/wpcontent/ uploads/2015/09/CodeMaster-QuickIN2.pdf>. Acesso em: 19 de out. 2016.

VON WANGENHEIM, C.G., VON WANGENHEIM, A. Ensinando Computação com Jogos. Bookess Editora, Florianópolis - SC, Brasil, 2012.

WING, J. M. Computational Thinking Benefits Society. Social Issues in Computing, 2014.

YAROSLAVSKI, D. Lightbot. 2014. Disponível em: <http://lightbot.com/Lightbot_How DoesLightbotTeachProgramming.pdf $>$. Acesso em: 19 de out. 2016. 